EGU21-16268

EGU General Assembly 2021

(c) Author(s) 2021. This work is distributed under

the Creative Commons Attribution 4.0 License.

\title{
Environmental Vulnerability Modeling in the Extensively Urbanized Arctic Center Integrating Remote Sensing, Landscape Mapping, and Local Knowledge
}

\author{
Sébastien Gadal ${ }^{1,2}$, Moisei Zakharov ${ }^{1,2}$, Jurate Kamicaityte ${ }^{3}$, Antonina Savvinova ${ }^{2}$, and Yuri Danilov² \\ ${ }^{1}$ Aix-Marseille Université, CNRS ESPACE UMR 7300, France (sebastien.gadal@univ-amu.fr) \\ ${ }^{2}$ North-Eastern Federal University, 670000 Yakutsk, Republic of Sakha, Russian Federation \\ ${ }^{3}$ Kaunas University of Technology, Faculty of Civil Engineering and Architecture, 51367 Kaunas, Lithuania
}

Arctic extensively urbanized centers are subject to the impact of many negative environmental phenomena progressing in terms of global climate change and regional development in Yakutia in the context of poor and missing databases. For this reason, the modeling of the risk exposures is based on combining the remote sensing, and local knowledge of inhabitants. According to the occurrences of the natural hazards, the territorial management and the decision-making system require the identification and assessment of natural risks to which the rural populations localized in the towns and villages are exposed, for example, in the urban center of Khamagatta located at $70 \mathrm{~km}$ to the North from Yakutsk near the Lena River. The main environmental vulnerability exposures are seasonal: springtime floods between May and June, the forest fires from June to August, the cyclic permafrost degradation, and river erosion impacts.

The current vulnerability impacts, damages to the lands and the settlements, and the populations risk exposures are analyzed from the maps of vulnerabilities created from remote sensing satellite Sentinel 2A/B series, with the local knowledge of the inhabitants of Khamagatta who lived and perceived all events. All the data generated, maps, models of vulnerability exposures, and local knowledge are integrated, combined, and merged into the geographic information system (GIS). The GIS modeling combines the risk of natural hazards and the damages, and the risk knowledge and perceptions of the inhabitants. Land uses, Landscape classification, and the land cover is made by Object-Based Image Analysis (OBIA) using an optical time series of Sentinel 2 images (2015-2020) including the population knowledge for the recognition of the environmental vulnerabilities. The methodological approach included the participation of local people in workshops through discussion and participatory mapping, questionnaires, and interviews in two stages. The first stage included the development of the knowledge database for a comprehensive understanding of the life of the local population, including the forms of adaptation to the negative natural phenomena. The collected information is delocalized and integrated into the GIS. The second stage consisted of validation and discussion, including stakeholders (municipality and rescue services) to increase the reliability and legitimacy of the research results.

Perceptions of the inhabitants of Khamagatta are correlated with the maps of risk exposures generated by remote sensing to increase the accuracy of the environmental process modeling and 
landscape classification. The combination of the environmental change dynamics, the impacts on the towns and villages with the human perception and experience constitutes the main base supporting the prevention mapping of the natural hazards. This data could be very useful in planning the development of Arctic towns and villages and proposing evolution scenarios and urban planning models and strategies for increasing their resilience and adaptation to climate change consequences. 